\title{
Volatile organic compounds for the control of Meloidogyne exigua in Coffea arabica
}

\author{
Willian R. J. Silva1, Alan R. T. Machado ${ }^{1}$, Viviane A. C. Campos ${ }^{1}$, Ana C. M. Zeri' ${ }^{2}$, Vicente P. Campos ${ }^{3}$ \& \\ Denilson F. Oliveira ${ }^{1}$
}

${ }^{1}$ Departamento de Química, Universidade Federal de Lavras, Cx. Postal 3037, 37200-000, Lavras, MG, Brazil; ${ }^{2}$ Laboratório Nacional de Biociências, Centro Nacional de Pesquisas em Energia e Materiais, Cx. Postal 6192, 13083-970, Campinas, SP, Brazil; ${ }^{3}$ Departamento de Fitopatologia, Universidade Federal de Lavras, Cx. Postal 3037, 37200-000, Lavras, MG, Brazil

Author for correspondence: Denilson F. Oliveira, e-mail: denilson@dqi.ufla.br

\begin{abstract}
Meloidogyne exigua is a plant-parasitic nematode that causes great losses to coffee farmers. Thus, to contribute to the development of new products to control this parasite, the present work studied the effect of volatile organic compounds (VOC) on the nematode and coffee plants (Coffea arabica), since these compounds are known to be used in plant defense against other agronomical pests. The number of galls of M. exigua was reduced when the aerial part of coffee plants was sprayed with combinations of methyl jasmonate + jasmone, (Z)-hex-3-en-1-ol + (E)-hex-3-en-1-ol + (Z)-hex-2-en-1-ol + (E)-hex-2-enal, (E)-hex-2-enyl acetate + hexyl acetate, meso-butane-2,3-diol + butane-1,2-diol + butane-1,3-diol + butane-1,4-diol, 3-hydroxybutan-2-one + 4-hydroxybutan-2-one or linalyl acetate + nerolidol. These VOC also caused alterations in the concentrations of substances such as alkaloids, phenols, amino acids and carbohydrates, in the roots of coffee plants. The findings suggest that these VOC may be explored as potential products for the control of $M$. exigua in coffee plants.

Key words: coffee plants, nematicides, root-knot nematode, volatile organic substances
\end{abstract}

\section{INTRODUCTION}

Among the plant-parasitic nematodes commonly found in coffee plantations is the root-knot nematode Meloidogyne exigua Goeldi. Although it is not as aggressive as other Meloidogyne species, this parasite can cause great losses to coffee producers (Barbosa et al., 2004; Campos \& Villain, 2005). Since the main methods to control this parasite are based on the use of nematicides that are harmful to human beings and to the environment, new products to reduce the population of $M$. exigua in coffee plants are needed (Campos \& Silva, 2008). One of the possible alternatives to satisfy the demand of coffee farmers involves the use of volatile organic compounds (VOC), which according to the literature are used in plant defense against pests and diseases (Rose et al., 1996; Paré \& Tumlinson, 1999; Roda \& Baldwin, 2003; Paré et al., 2005; Arimura et al., 2005). Methyl jasmonate (Rodriguez-Saona et al., 2001) can be used to illustrate the potential of VOC, since this substance activates defense genes in plants (Bate et al., 1998). For example, Solanum lycopersicum L. exposed to this substance produces the protein LePR-5, which plays an important role in the plant response to abiotic stress and is involved in the plant defense against pathogens (Ren et al., 2011). The resistance of Avena sativa L. to the nematodes Heterodera Avenae Wollenweber and Pratylenchus neglectus (Rensch) Filipjev \& Schuurmans Stekhoven increases when this plant is exposed to methyl jasmonate
(Soriano et al., 2004). VOC like (Z)-hex-3-enyl acetate, $\beta$-ocimene, (R)-linalool, (3E)-4,8-dimethylnona-1,3,7triene, methyl salicylate, (Z)-jasmone, $\beta$-caryophyllene and (3E,7E)-4,8,12-trimethyltrideca-1,3,7,11-tetraene, which are all of plant origin, are also potentially useful for the control of plant pathogens, since Phaseolus lunatus L. exposed to combinations of these substances increased its response to artificial damage by $180 \%$ (Heil \& Kost, 2006).

Given the great potential of VOC for the development of new products for controlling pests and diseases of plants, and the increasing demand for new methods to control $M$. exigua in coffee plantations, the present work investigated the effect of VOC on this nematode and on the metabolite production of Coffea arabica L. not exposed to the nematode.

\section{MATERIALS AND METHODS}

\section{Volatile organic compounds (VOC)}

Substances were acquired (Sigma or Aldrich) and used as received. They were dissolved in an aqueous 0.01 $\mathrm{g} \mathrm{L}^{-1}$ Tween 80 solution to form six different combinations that constituted the treatments (values between parenthesis are purity according to the manufacturer): treatment 1 : jasmone $(90 \%)+$ methyl jasmonate $(95 \%)$; treatment $2:(Z)$ hex-3-en-1-ol (97\%) + (E)-hex-3-en-1-ol (98\%) + (Z)-hex2-en-1-ol (95\%) + (E)-hex-2-enal (98\%); treatment 3: (E)- 
hex-2-enyl acetate $(99 \%)+$ hexyl acetate $(99 \%)$; treatment 4: meso-butane-2,3-diol (97\%) + butane-1,2-diol (98\%) + butane-1,3-diol (93\%) + butane-1,4-diol (99\%); treatment 5: 3-hydroxybutan-2-one (96\%) + 4-hydroxybutan-2one $(95 \%)$; treatment 6: linalyl acetate $(97 \%)+$ nerolidol $(98 \%)$. These substances were chosen due to their ability to increase the resistance of plants to diseases and to insects (Martin et al., 2002; Ryu et al., 2003; Ryu et al., 2004; Kost et al., 2006; Kishimoto et al., 2006), and mixed according to their structural similarities in order to reduce the number of treatments. Three different concentrations were used for each substance: $0.5,1.0$ or $2.5 \mathrm{mmol} \mathrm{L}^{-1}$.

\section{Nematode inoculum}

M. exigua was characterized using morphological characteristics and female electrophoresis. Then, roots of coffee plants (Coffea arabica L. cv. Catuaí 144) infected with $M$. exigua and grown in a greenhouse were carefully washed and cut into $1.0 \mathrm{~cm}$ pieces to be crushed for $40 \mathrm{sec}$ with an aqueous $0.005 \mathrm{~g} \mathrm{~mL}^{-1}$ sodium hypochlorite solution in a blender (Hussey \& Barker, 1973). Eggs retained in a 500-mesh sieve were transferred to a Baermann funnel (Whitehead \& Heming, 1965) and those second-stage juveniles (J2) of M. exigua that hatched 24-48 h after the eggs were placed in the funnel were used in the experiments.

\section{Effect of VOC on the infectivity of Meloidogyne exigua}

Seedlings of coffee plants (Coffea arabica L. cv. Catuaí 144) containing three pairs of leaves were transplanted into $3 \mathrm{~L}$ plastic vessels containing a sterile mixture of sand:soil $(1: 1, \mathrm{v} / \mathrm{v})$. After 15 days in a greenhouse, at the end of the afternoon, their aerial parts were sprayed with the VOC solutions until they began to drip. For each group of VOC described above, two concentrations were employed (0.5 or $\left.1.0 \mathrm{mmol} \mathrm{L}^{-1}\right)$ for each substance. Two days later, an aqueous suspension $(10 \mathrm{~mL})$ containing nearly $3,000 \mathrm{M}$. exigua J2 was added to the substrate of each coffee plant through four equidistant cylindrical holes $(0.5 \mathrm{~cm}$ wide and $4.0 \mathrm{~cm}$ deep) in the substrate, around the plant (about $2 \mathrm{~cm}$ distant from the stem).

As experiments carried out with Meloidogyne incognita (Kofoid \& White) Chitwood in tomato plants (Solanum lycopersicum L.) suggests that the effect of VOC like methyl jasmonate only lasts for about one week (Fujimoto et al., 2011), a second application of the VOC solutions was done five days after the $M$. exigua inoculation to ensure that all individuals penetrating plant roots would feel changes possibly caused by the VOC combinations. The experiment was conducted in a randomised block design, employing three replicates per treatment and per concentration, in the Summer. Each replicate comprised three plants. Tween 80 at $0.01 \mathrm{~g} \mathrm{~mL}^{-1}$ was used as control. The development of $M$. exigua in coffee roots is naturally slow, since in greenhouse experiments only one female with less than 20 eggs is usually observed per plant 44 days after the inoculation of the nematode $\mathrm{J} 2$ in coffee plants (Lordello
\& Lordello, 1983). Therefore, longer period of time than usually employed in experiments with other species in the Meloidogyne genus is necessary to observe significant difference between treatments and control. Consequently, one-hundred-and-ten days after the nematode inoculation roots were removed from the vessels, washed with water, dried with paper towels and weighed. Then, galls were counted. Values were divided by the masses of fresh roots, followed by transformation of the resulting numbers into logarithms to be submitted to statistical analysis. The experiment was repeated twice, with similar results. Therefore only one set of data is herein presented.

\section{In vitro effect of VOC on Meloidogyne exigua}

Three different concentrations were used for each substance present in the combinations of VOC described above $\left(0.5,1.0\right.$ and $\left.2.5 \mathrm{mmol} \mathrm{L}^{-1}\right)$. Adapting a method described in the literature (Amaral et al., 2003), aliquots $(100 \mu \mathrm{L})$ of the VOC solutions and an aqueous suspension $(20 \mu \mathrm{L})$ containing approximately $25 \mathrm{M}$. exigua $\mathrm{J} 2$ were poured into $350 \mu \mathrm{L}$ cells of a 96-cell polypropylene plate. Six replicates were used for each treatment and concentration, and an aqueous $0.01 \mathrm{~g} \mathrm{~mL}^{-1}$ Tween 80 solution was employed as the control. After $48 \mathrm{~h}$ at $25^{\circ} \mathrm{C}$, one drop of a freshly prepared $1.0 \mathrm{~mol} \mathrm{~L}^{-1} \mathrm{NaOH}$ solution was added to the content of each cell and nematodes were counted using an inverted microscope. $\mathrm{J} 2$ that changed their body shape from straight to curled or hook-shaped within 3 min were considered to be alive, whereas the nematodes that did not respond to the addition of $\mathrm{NaOH}$ were considered dead. Values were transformed into percentages before the statistical analysis.

\section{In vitro nematicidal activity of extracts from roots of plants sprayed with VOC}

This experiment was carried out to detect nonvolatile substances produced by plants after their contact with VOC. Coffee seedlings were prepared and sprayed with VOC as described above. The experiment was conducted in a randomised block design, employing four replicates per treatment and per concentration. Each plot comprised one plant and Tween 80 at $0.01 \mathrm{~g} \mathrm{~mL}^{-1}$ was used as a control. Four days later, roots were removed from the vessels, washed with water, freeze-dried, ground with a mortar and pestle, and stored in a freezer at $-10^{\circ} \mathrm{C}$. Aliquots $(250 \mathrm{mg})$ of the dry and ground roots were immersed in $10 \mathrm{~mL}$ methanol for $24 \mathrm{~h}$. Each resulting mixture was filtered through cottonwool plugs and all residues underwent four more extractions with methanol ( $10 \mathrm{~mL}$ for each one). The liquid phases from the five extractions were combined, concentrated to dryness in a rotary evaporator and freeze-dried. Aliquots $(5 \%)$ of the final residues were dissolved in $1.0 \mathrm{~mL}$ of an aqueous $0.01 \mathrm{~g}$ $\mathrm{mL}^{-1}$ Tween 80 solution to be submitted to the in vitro assay with $M$. exigua $\mathrm{J} 2$ as described above. The experiment was repeated twice, with similar results. Therefore only one set of data is herein presented. 


\section{Quantifications of amino acids and carbohydrates}

As described elsewhere (Passos, 1996), the dry and ground roots $(250 \mathrm{mg})$ obtained as described above underwent two extractions for $10 \mathrm{~min}$ with $20 \mathrm{~mL}$ of a methanol:chloroform:water solution (MCA; 12:5:3, v/v). After filtration through cotton-wool plugs, the liquid phases from both extractions were combined and added to decanting funnels containing $30 \mathrm{~mL}$ chloroform and $60 \mathrm{~mL}$ water. After vigorous stirring, the aqueous phases were separated, concentrated to dryness in a rotary evaporator and freeze-dried. Each of the final residues was dissolved in water to a total volume of $25 \mathrm{~mL}$, resulting in solution "A", which was used for the quantification of amino acids and carbohydrates.

For the quantification of amino acids, aliquots $(0.5 \mathrm{~mL})$ of each solution "A" were transferred in triplicate to test tubes containing a ninhidrin solution (25 $\mathrm{mL} \mathrm{NaOAc.} 3 \mathrm{H}_{2} \mathrm{O}$ at $1.36 \mathrm{~g} \mathrm{~mL}^{-1}$ (pH 5.5), $20 \mathrm{~mL}$ glacial acetic acid, $75 \mathrm{~mL}$ ethyleneglycol monomethyl ether, 0.2 $\mathrm{g}$ ninhidrin and $30 \mathrm{mg}$ hydrindantin). The tubes were agitated and then maintained in a waterbath at $100^{\circ} \mathrm{C}$ for $15 \mathrm{~min}$. A solution $(3.0 \mathrm{~mL})$ of ethanol:water $(1: 1, \mathrm{v} / \mathrm{v})$ was added to the content of each tube. After cooling to room temperature, absorbance of the resulting solutions was measured in a Spectrum AP1105 spectrophotometer, at $570 \mathrm{~nm}$, using glass cuvettes. Values were transformed into amino acid concentrations by comparison with an analytical curve that was obtained using L-leucine (purity: $98.5 \%$ ) at the following concentrations: 0,40 , 60, 80, $100120,160,180,200,250$ and $300 \mu \mathrm{g} \mathrm{mL}^{-1}$.

For the quantification of carbohydrates, aliquots $(1.0 \mathrm{~mL})$ of each solution " $\mathrm{A}$ " were poured in triplicate into test tubes containing $0.5 \mathrm{~mL}$ of an aqueous $0.05 \mathrm{~g}$ $\mathrm{mL}^{-1}$ phenol solution. Concentrated sulphuric acid (2.5 $\mathrm{mL}$ ) was added to the contents of each tube, which was kept at rest for $10 \mathrm{~min}$, then incubated in a water bath at $30^{\circ} \mathrm{C}$ for $15 \mathrm{~min}$, and the absorbances were measured at $490 \mathrm{~nm}$. Values were transformed into carbohydrate concentrations by comparison with an analytical curve obtained using D-glucose (purity: 99.9\%) at $0,1,10,20$, $40,60,80,100,120$ and $140 \mu \mathrm{g} \mathrm{mL}^{-1}$.

Specifically for the quantification of sucrose, each solution " $\mathrm{A}$ " $(1.0 \mathrm{~mL})$ was transferred in triplicate to a test tube, freeze-dried and dissolved in $0.1 \mathrm{~mL}$ water. An aqueous $0.3 \mathrm{~g} \mathrm{~mL}^{-1} \mathrm{KOH}$ solution $(0.1 \mathrm{~mL})$ was added to the contents of each tube, which were immersed in a water bath at $100^{\circ} \mathrm{C}$ for $10 \mathrm{~min}$. This procedure prevents the interference of other carbohydrates in the quantification of sucrose (Passos, 1996). After cooling to room temperature, $5 \mathrm{~mL}$ of an anthrone solution $(600$ $\mathrm{mg}$ anhydrous anthrone, $270 \mathrm{~mL}$ concentrated sulphuric acid and $30 \mathrm{~mL}$ water) was poured into each tube, which was then maintained in a water bath at $40^{\circ} \mathrm{C}$ for $10-15 \mathrm{~min}$. Absorbance was then measured at $620 \mathrm{~nm}$. Values were converted into sucrose concentrations by comparison with an analytical curve obtained using sucrose (purity: 99.9\%) at $0,1,10,20,40,60,80,100,120,140,160$ and $200 \mu \mathrm{g}$ $\mathrm{mL}^{-1}$.

\section{Quantification of phenols}

Adapting a method described in the literature (AOAC, $1960)$, the freeze-dried and ground roots $(200 \mathrm{mg}$ ) obtained as described above and $12.5 \mathrm{~mL}$ of a methanol:water solution $(1: 1, \mathrm{v} / \mathrm{v})$ were poured into round-bottomed flasks, to which reflux condensers were attached. After refluxing the content of each flask for $15 \mathrm{~min}$, each mixture was filtered through cotton-wool plugs and all residues underwent one more extraction. Both filtrates were combined and the total volume was adjusted to $25 \mathrm{~mL}$ with water. Aliquots of the resulting solutions $(20 \mu \mathrm{L})$ in triplicate were poured into test tubes, into which were also poured $1.68 \mathrm{~mL}$ water, $100 \mu \mathrm{L}$ of the Folin-Denis reagent (2.5 g sodium tungstate dihydrate, 0.5 $\mathrm{g}$ fosfomolibdic acid, $1.25 \mathrm{~mL}$ phosphoric acid, and water to complete the volume to $25 \mathrm{~mL}$ ) and $200 \mu \mathrm{L}$ of an aqueous $0.02 \mathrm{~g} \mathrm{~mL}^{-1}$ sodium carbonate solution. Then, absorbances were measured at $720 \mathrm{~nm}$ and values underwent conversion to phenol concentration by comparison with an analytical curve obtained using tannic acid (purity: $99.9 \%$ ) at $0,3,7$, 11,15 and $19 \mu \mathrm{g} \mathrm{mL}^{-1}$.

\section{Quantification of alkaloids}

Adapting a method for the quantification of alkaloids (Sreevidya \& Mehrotra, 2003), the freeze-dried and ground roots $(500 \mathrm{mg})$ were submitted to three extractions $(10 \mathrm{~min}$ each) with an acetic acid:water $(2: 98, \mathrm{v} / \mathrm{v})$ solution $(10 \mathrm{~mL}$ in each extraction). The liquid phases from the extractions were combined to result in solutions from which three aliquots $(5 \mathrm{~mL}$ each) were withdrawn and mixed with $2.0 \mathrm{~mL}$ of the Dragendorff reagent $\left[8.0 \mathrm{~g} \mathrm{Bi}\left(\mathrm{NO}_{3}\right)_{3} 60\right.$ $\mathrm{mL}$ water, $10 \mathrm{~mL}$ glacial acetic acid, $8.0 \mathrm{KI}]$ in test tubes. The resulting mixtures were centrifuged ( $818 \mathrm{~g} \mathrm{x} 30 \mathrm{~min})$ to afford precipitates that were separated from the liquid phase, washed with ethanol $(2 \times 4 \mathrm{~mL})$ and treated with an aqueous $0.01 \mathrm{~g} \mathrm{~mL}^{-1}$ sodium sulphide solution $(2.0 \mathrm{~mL})$. After centrifugation and removal of the liquid phases, the new precipitates were dissolved in concentrated $\mathrm{HNO}_{3}(2.0$ $\mathrm{mL}$ ) and diluted with water to $10 \mathrm{~mL}$. Aliquots of the final solutions $(1.0 \mathrm{~mL})$ were added to an aqueous $0.03 \mathrm{~g} \mathrm{~mL}^{-1}$ thiourea solution $(5 \mathrm{~mL})$ and absorbances were measured at $435 \mathrm{~nm}$. Values underwent conversion to concentration of alkaloids by comparison with an analytical curve obtained using brucine (purity: 98\%) at $0,50,100,150,200,250$, $300,350,400,450$ and $500 \mu \mathrm{g} \mathrm{mL}^{-1}$.

\section{Analysis by hydrogen nuclear magnetic resonance $\left({ }^{1} \mathrm{H}\right.$ NMR)}

Aliquots $(13.33 \mathrm{mg})$ of the freeze-dried extracts, obtained as described in the quantification of amino acids and carbohydrates, were dissolved in $250 \mu \mathrm{L}$ buffered phosphate (Mallinckrodt Baker) solution ( $\mathrm{pH} 7.5)$ at 50 mmol L-1 that was prepared with deuterated water $\left(\mathrm{D}_{2} \mathrm{O}\right.$, Cambridge Isotope Laboratory) containing sodium 2,2- 
dimethyl-2-silapentane-5-sulfonate (DSS; Cambridge Isotope Laboratory) at $0.5 \mathrm{mmol} \mathrm{L} \mathrm{L}^{-1}$, which was used as internal reference. The ${ }^{1} \mathrm{H}$ NMR spectra were acquired on a Varian AS $500(500 \mathrm{MHz})$ spectrometer, using $90^{\circ}$ hard pulses. Thirty-two scans were carried out for each sample, with acquisition time equal to $4 \mathrm{sec}$. In order to identify and quantify as much metabolites as possible, we used the software Chenomx Suite 6.0 (Chenomx Inc.), employing the databank of the program and those available at the Biological Magnetic Resonance Data Bank (www.bmrb. wisc.edu) and Colmar Suite of Web Servers (spinportal. magnet.fsu.edu).

\section{Statistical analysis}

Values underwent analysis of variance (ANOVA) and means were separated according to the Scott \& Knott (1974) test $(P \leq 0.05)$. For this purpose, the software SISVAR 5.1 (Sistema para Análises Estatísticas, UFLA, Lavras, 2006) was used. ${ }^{1} \mathrm{H}$ NMR spectra were converted in the $0.02-4.50 \mathrm{ppm}$ and 5.00-9.98 ppm ranges, into a table of peak area versus $0.04 \mathrm{ppm}$ intervals to be submitted to principal component analysis (PCA) with the software Pirouette 3.11, using the default parameters of this software (Infometrix, Inc.).

\section{RESULTS}

\section{Effect of VOC on the infectivity of Meloidogyne exigua}

No statistical difference was observed for the mass of roots, the mean value of which was $21.4 \pm 2.8 \mathrm{~g}$ (mean \pm standard deviation). However, the number of galls per mass of coffee root (Table 1) decreased when the following combinations of VOC were sprayed on the aerial parts of plants: jasmone + methyl jasmonate (treatment 1 at $0.5 \mathrm{mmol}$ $\mathrm{L}^{-1}$ ); (Z)-hex-3-en-1-ol + (E)-hex-3-en-1-ol + (Z)-hex-2-en1-ol $+(E)$-hex-2-enal (treatment 2 at both concentrations); (E)-hex-2-enyl acetate + hexyl acetate (treatment 3 at both concentrations); meso-butane-2,3-diol + butane-1,2-diol + butane-1,3-diol + butane-1,4-diol (treatment 4 at $0.5 \mathrm{mmol}$
$\mathrm{L}^{-1}$ ); and 3-hydroxybutan-2-one + 4-hydroxybutan-2-one (treatment 5 at $0.5 \mathrm{mmol} \mathrm{L}^{-1}$ ).

\section{In vitro effect of $\mathrm{VOC}$ on Meloidogyne exigua}

At the lowest concentration $\left(0.5 \mathrm{mmol} \mathrm{L}^{-1}\right)$, none of the VOC combinations affected the mortality of $M$. exigua J2. When the concentrations of the substances were increased to 1.0 and $2.5 \mathrm{mmol} \mathrm{L}^{-1}$, only the combinations of jasmone + methyl jasmonate (treatment 1$)$ and (Z)-hex-3en-1-ol + (E)-hex-3-en-1-ol + (Z)-hex-2-en-1-ol + (E)-hex2-enal (treatment 2 ) afforded values of dead J2 statistically above that observed for the control (Table 2).

\section{Metabolic alterations in the roots of coffee plants sprayed with VOC}

Several alterations in the metabolic production of plants were observed (Figure 1 and 2). For example, in all roots treated with VOC at $0.5 \mathrm{mmol} \mathrm{L}^{-1}$ (treatments 1-6) the concentration of alkaloids was lower than that in plants treated with the control (Tween 80). However, except for treatment 1 at $1.0 \mathrm{mmol} \mathrm{L}^{-1}$, which also decreased the concentration of alkaloids in plant roots, all the others combinations with each substance at $1.0 \mathrm{mmol} \mathrm{L}^{-1}$ (treatments 2-6) caused no alteration in the concentration of these metabolites. Similarly, the concentration of amino acids for all treatments were statistically equal or just a little lower than that observed for the control, although sucrose and total carbohydrate concentrations varied widely, while all VOC combinations reduced the concentration of phenols (Figure 1). Ten substances were identified and quantified by ${ }^{1} \mathrm{H}$ NMR analysis (Figure 2). For malic acid, aspartic acid, chorismic acid, chlorogenic acid, asparagine, (Z)-hex-3-en1-ol, trigonelline and choline, concentrations in the roots of plants sprayed with VOC were always statistically equal or lower than that observed for the control. For citric acid and alanine, concentrations varied widely. According to the PCA of the ${ }^{1} \mathrm{H}$ NMR spectra, $99.9 \%$ of the variance could be explained by twelve components, the two first of them being responsible for $87.8 \%$ of such variance

TABLE 1 - Galls of Meloidogyne exigua in the roots of coffee plants sprayed in their aerial parts with solutions of volatile organic compounds (VOC) at 0.5 and $1.0 \mathrm{mmol} \mathrm{L}^{-1}$

\begin{tabular}{|c|c|c|c|}
\hline \multirow[t]{2}{*}{ Treatment number } & \multirow[t]{2}{*}{ VOC solutions and control } & \multicolumn{2}{|c|}{ Galls per mass of root $\left(\mathrm{g}^{-1}\right)^{1,2}$} \\
\hline & & $0.5^{3}$ & $1.0^{3}$ \\
\hline 1 & Jasmone + methyl jasmonate & $12.3 \mathrm{~b}$ & $6.0 \mathrm{a}$ \\
\hline 2 & (Z)-hex-3-en-1-ol + (E)-hex-3-en-1-ol + (Z)-hex-2-en-1-ol + (E)-hex-2-enal & $8.0 \mathrm{a}$ & $7.0 \mathrm{a}$ \\
\hline 3 & (E)-hex-2-enyl acetate + hexyl acetate & $3.3 \mathrm{a}$ & $7.0 \mathrm{a}$ \\
\hline 4 & meso-butane-2.3-diol + butane-1.2-diol + butane-1.3-diol + butane-1.4-diol & $4.6 \mathrm{a}$ & $11.6 \mathrm{~b}$ \\
\hline 5 & 3-hydroxybutan-2-one +4 -hydroxybutan-2-one & $4.0 \mathrm{a}$ & $10.3 \mathrm{~b}$ \\
\hline 6 & Linalil acetate + nerolidol & $16.0 \mathrm{~b}$ & $12.0 \mathrm{~b}$ \\
\hline 7 & Tween 80 (control at $\left.0.01 \mathrm{~g} \mathrm{~mL}^{-1}\right)^{4}$ & $25.6 \mathrm{~b}$ & $25.6 \mathrm{~b}$ \\
\hline
\end{tabular}

${ }^{1}$ Values followed by the same letter do not differ significantly according to the Scott \& Knott test $(P \leq 0.05) ;{ }^{2}$ Masses of roots were statistically equal for all treatments; ${ }^{3} \mathrm{VOC}$ concentrations in $\mathrm{mmol} \mathrm{L}^{-1} ;{ }^{4} \mathrm{All} \mathrm{VOC}$ solutions were prepared by dissolving volatile organic substances in an aqueous $0.01 \mathrm{~g} \mathrm{~mL}^{-1}$ Tween 80 solution. 
Volatile organic compounds for the control of Meloidogyne exigua in Coffea arabica

TABLE 2 - In vitro mortality of Meloidogyne exigua second-stage juveniles (J2) exposed to combinations of volatile organic compounds (VOC) at three different concentrations

\begin{tabular}{|c|c|c|c|c|}
\hline \multirow[t]{2}{*}{ Treatment } & \multirow[t]{2}{*}{ VOC solutions and control } & \multicolumn{3}{|c|}{ Dead J2 (\%) ${ }^{1}$} \\
\hline & & $0.5^{3}$ & $1.0^{3}$ & $2.5^{3}$ \\
\hline 1 & Jasmone + methyl jasmonate & $19.0 \mathrm{a}$ & $21.6 \mathrm{a}$ & $41.5 \mathrm{~b}$ \\
\hline 2 & (Z)-hex-3-en-1-ol + (E)-hex-3-en-1-ol + (Z)-hex-2-en-1-ol + (E)-hex-2-enal & $23.3 \mathrm{a}$ & $48.9 \mathrm{~b}$ & $91.9 \mathrm{c}$ \\
\hline 3 & (E)-hex-2-enyl acetate + hexyl acetate & $19.4 \mathrm{a}$ & $16.1 \mathrm{a}$ & $16.7 \mathrm{a}$ \\
\hline 4 & meso-butane-2,3-diol + butane-1,2-diol + butane-1,3-diol + butane-1,4-diol & $19.9 \mathrm{a}$ & $16.1 \mathrm{a}$ & $21.5 \mathrm{a}$ \\
\hline 5 & 3-hydroxybutan-2-one +4 -hydroxybutan-2-one & $23.1 \mathrm{a}$ & $19.9 \mathrm{a}$ & $12.6 \mathrm{a}$ \\
\hline 6 & Linalil acetate + nerolidol & $22.5 \mathrm{a}$ & $29.7 \mathrm{a}$ & $21.1 \mathrm{a}$ \\
\hline 7 & Tween 80 (control at $\left.0.01 \mathrm{~g} \mathrm{~mL}^{-1}\right)^{2}$ & $5.3 \mathrm{a}$ & $5.3 \mathrm{a}$ & $5.3 \mathrm{a}$ \\
\hline
\end{tabular}

${ }^{1}$ Values followed by the same letter do not differ significantly according to the Scott \& Knott test $(P \leq 0.05) ;{ }^{2}$ All VOC solutions were prepared by dissolving volatile organic substances in an aqueous $0.01 \mathrm{~g} \mathrm{~mL}^{-1}$ Tween 80 solution; ${ }^{3} \mathrm{VOC}$ concentrations in $\mathrm{mmol} \mathrm{L}^{-1}$.

(Figure 3). Among the most significant differences are the values observed for treatments 1 (at both concentrations) and 2 (at $0.5 \mathrm{mmol} \mathrm{L}^{-1}$ ), which were more distant from the control.

Although the root extracts from plants sprayed with VOC present in treatments 3 (at $0.5 \mathrm{mmol} \mathrm{L}^{-1}$ ), 1 and 6 (both at $1.0 \mathrm{mmol} \mathrm{L}^{-1}$ ), caused no alteration in the in vitro mortality of M. exigua $\mathrm{J} 2$, all the other treatments increased the percentage of dead J2 (Table 3). Among the most active extracts were those from plants sprayed with (E)-hex-2-enyl acetate + hexyl acetate (treatment 3 at $1.0 \mathrm{mmol} \mathrm{L}^{-1}$ ) and meso-butane-2,3-diol + butane-1,2-diol + butane-1,3-diol + butane-1,4-diol (treatment 4 at both concentrations).

\section{DISCUSSION}

One of the best results in the in vivo test was observed for the combination of hexyl acetate $+(E)$-hex2-enyl acetate (treatment 3), which reduced the number of galls at both concentrations used in the experiment (Table 1). This result is in accordance with the higher production of hexyl acetate by Vaccinium corymbosum L. attacked by Lymatria dispar L., suggesting that this substance may be part of the defense mechanisms in plants (Rodriguez-Saona, 2001). Similarly, (E)-hex-2-enyl acetate has been reported to activate plant defense mechanism (Kost \& Heil, 2006; Ruther \& Kleier, 2005; Engelberth et al., 2004).

Once the potential of the combination of hexyl acetate $+(E)$-hex-2-enyl acetate for controlling the population of $M$. exigua in coffee fields was evident, a search for clues about the mode of action of such substances was carried out. Firstly, their possible nematicidal activity was investigated, since other VOC have already been reported as directly active against Meloidogyne spp (Ibraim et al., 2006; Ntalli et al., 2011; Caboni et al., 2012). However, no in vitro activity of these substances against $M$. exigua could be observed even at the highest concentration $\left(2.5 \mathrm{mmol} \mathrm{L}^{-1}\right)$, suggesting that they act indirectly against the nematode (Table 2), perhaps by activating plant defense mechanisms.
To further investigate the mode of action of the substances in treatment 3 (Table 1), root extracts from plants sprayed with these substances at a concentration of 0.5 and $1.0 \mathrm{mmol} \mathrm{L}^{-1}$ were tested for in vitro activity against $M$. exigua. The extract of plants sprayed with the most concentrated solution $\left(1.0 \mathrm{mmol} \mathrm{L}^{-1}\right)$ of treatment 3 increased the number of dead J2 (Table 3), suggesting that these compounds can induce the production of non-volatile nematicidal substances by coffee plants. Furthermore, treatment 3 (at 0.5 and $1.0 \mathrm{mmol} \mathrm{L}^{-1}$ ) increased the concentration of sucrose (Figure 1), which can block the action of cytokinins that are important for the formation and maintenance of the nematode feeding site in plant roots (Ikeda et al., 1999; Lohar et al., 2004). As the number of galls of M. exigua in plants sprayed with these VOC at both concentrations (treatment 3 ) are statistically equal (Table 1 ), the increase in the sucrose concentration appears to be more important for the control of $M$. exigua in coffee plants than the production of nematicidal substances.

Other metabolic differences were observed in the roots of plants exposed to this treatment at both concentrations (Figure 1 and 2). For example, the concentration of alkaloids was higher in plants exposed to treatment 3 at $1.0 \mathrm{mmol} \mathrm{L}^{-1}$ than in those exposed to the same combination of VOC at $0.5 \mathrm{mmol} \mathrm{L}^{-1}$. This result may be particularly important if one takes into account the reported nematicidal activity by various alkaloids (Chitwood, 2002). Also worthy of mention is the use of alkaloids by plants to defend themselves from other pathogens or insects (Simons et al., 2006; Keeling \& Bohlmann, 2006). Nevertheless, the concentrations of alkaloids in the roots of plants exposed to treatment 3 at $1.0 \mathrm{mmol} \mathrm{L}^{-1}$ and the control are statistically equal (Figure 1), suggesting that the concentration of these substances in the roots has no influence on the mortality of $\mathrm{J} 2$ exposed to the plant extracts, or that plants exposed to the higher concentration of treatment 3 produced the same amount of total alkaloids that was produced by the control plants, but increased the concentrations of those ones active against $M$. exigua. A reverse situation was observed for amino acids, the concentration of which was 

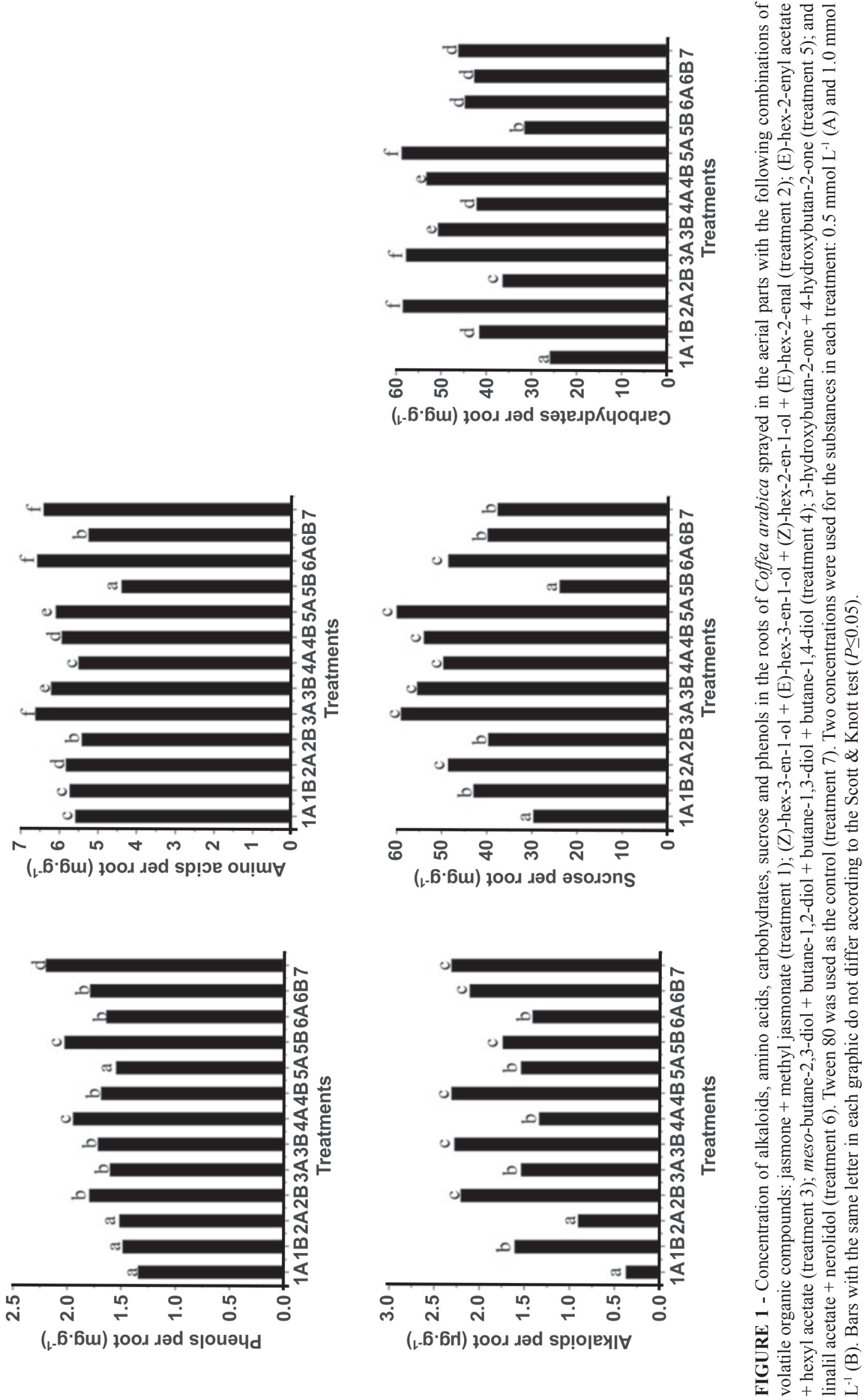

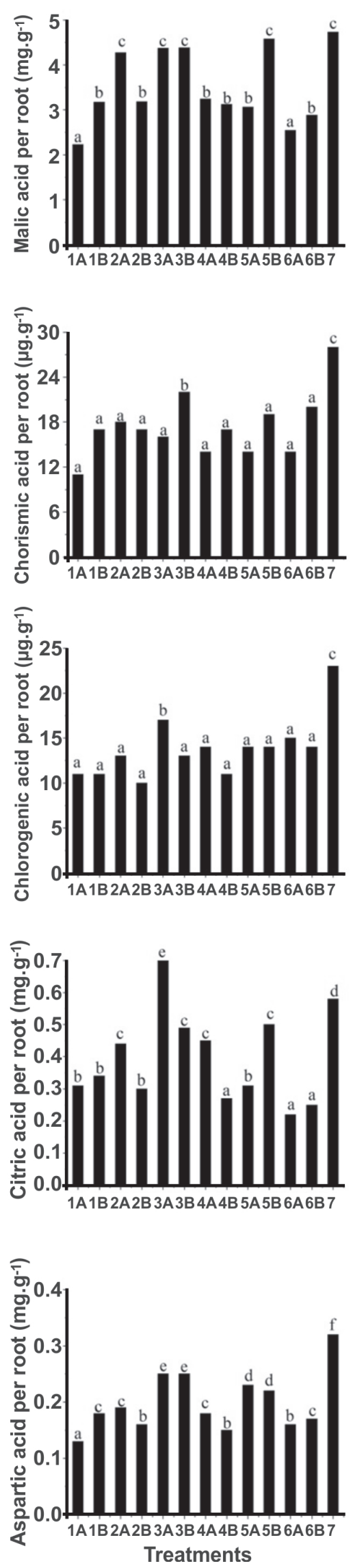
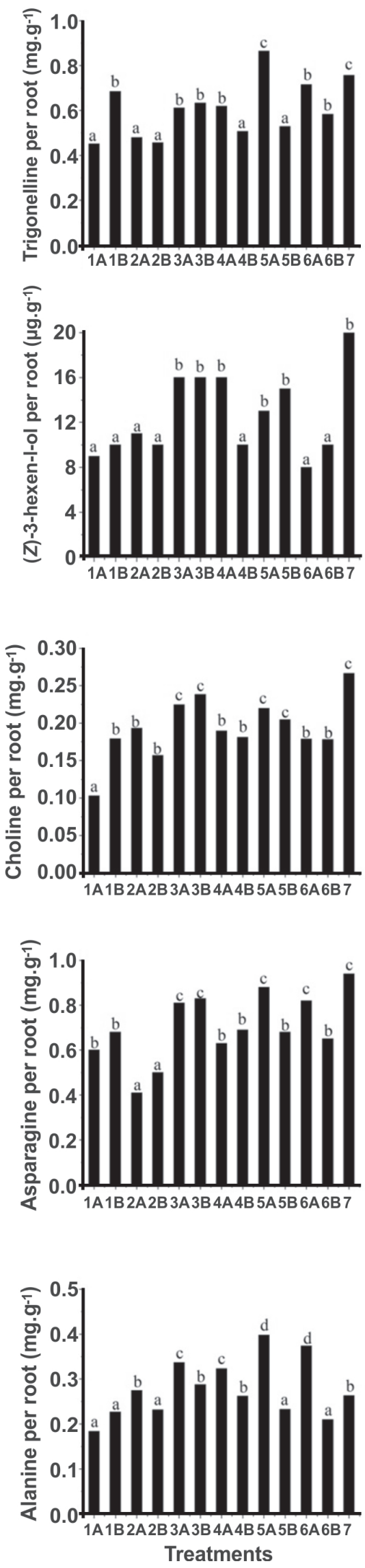

FIGURE 2 - Concentration of substances identified and quantified in the roots of coffee plants (Coffea arabica) using hydrogen nuclear magnetic resonance spectroscopy. Plants were sprayed with the following combinations of volatile organic compounds: jasmone + methyl jasmonate (treatment 1); (Z)hex-3-en-1-ol + (E)-hex-3-en-1-ol + (Z)-hex-2-en-1-ol + (E)-hex-2-enal (treatment 2); (E)-hex-2-enyl acetate + hexyl acetate (treatment 3); mesobutane-2,3-diol + butane-1,2-diol + butane-1,3-diol + butane-1,4-diol (treatment 4); 3-hydroxybutan-2-one + 4-hydroxybutan-2-one (treatment 5); and linalil acetate + nerolidol (treatment 6). Tween 80 was used as the control (treatment 7). Two concentrations were used for substances in each treatment: $0.5 \mathrm{mmol} \mathrm{L}^{-1}(\mathrm{~A})$ and $1.0 \mathrm{mmol} \mathrm{L}^{-1}(\mathrm{~B})$. Bars with the same letter in each graph do not differ significantly according to the Scott \& Knott Test $(P \leq 0.05)$. 


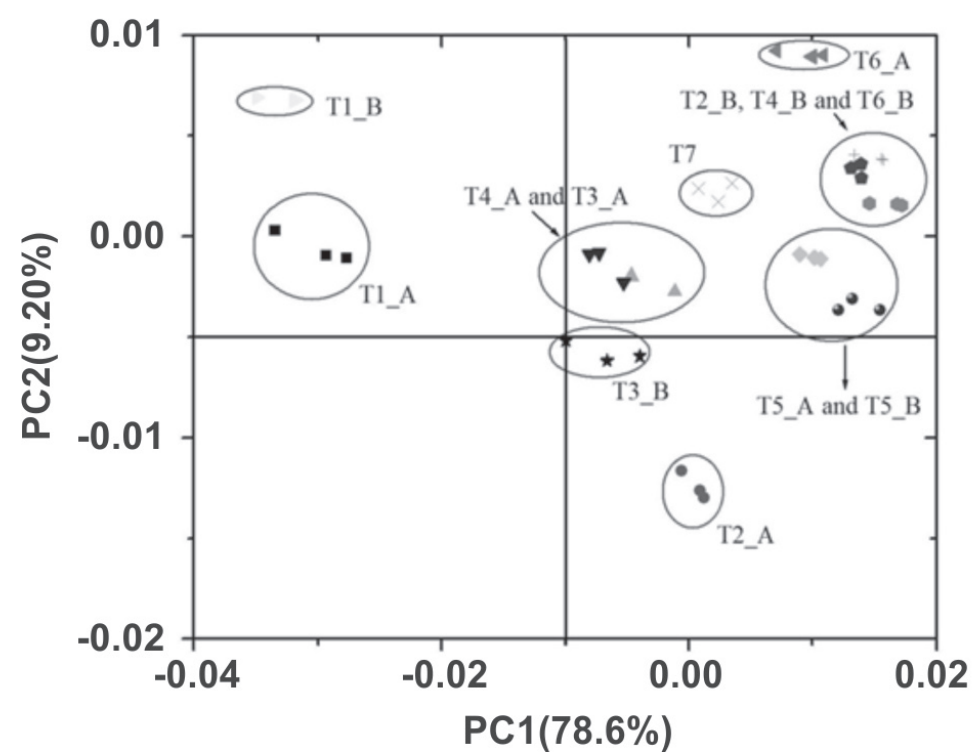

FIGURE 3 - Scores of the principal component analysis (Tx_y: $\mathrm{x}$ and y correspond to treatment and concentration, respectively) of the hydrogen nuclear magnetic resonance spectra, which were obtained from the extracts of roots from Coffea arabica sprayed with the following combinations of volatile organic compounds: jasmone + methyl jasmonate (treatment 1); (Z)-hex-3-en-1-ol + (E)-hex-3-en-1-ol $+(\mathrm{Z})$-hex-2-en-1-ol + (E)-hex-2-enal (treatment 2); (E)-hex-2-enyl acetate + hexyl acetate (treatment 3); meso-butane-2,3-diol + butane-1,2-diol + butane-1,3diol + butane-1,4-diol (treatment 4); 3-hydroxybutan2-one + 4-hydroxybutan-2-one (treatment 5); and linalil acetate + nerolidol (treatment 6 ). Tween 80 was used as the control (treatment 7). Two concentrations were used for each treatment: $0.5 \mathrm{mmol} \mathrm{L}^{-1}(\mathbf{A})$ and $1.0 \mathrm{mmol} \mathrm{L}^{-1}(\mathbf{B})$. Only the first (PC1: $9.2 \%$ of the variance) and the second (PC2: $78.6 \%$ of the variance) component of the analysis were considered in the graphic, which takes into account three replicates per treatment and concentration.

TABLE 3 - In vitro mortality of Meloidogyne exigua second-stage juveniles (J2) exposed to extracts from roots of coffee plants sprayed with combinations of volatile organic compounds (VOC) at two different concentrations

\begin{tabular}{|c|c|c|c|}
\hline \multirow[t]{2}{*}{ Treatment } & \multirow[t]{2}{*}{ VOC solutions and control } & \multicolumn{2}{|c|}{ Dead J2 (\%) $)^{1}$} \\
\hline & & $0.5^{4}$ & $1.0^{4}$ \\
\hline 1 & Jasmone + methyl jasmonate & $19.3 \mathrm{~b}$ & $1.78 \mathrm{a}$ \\
\hline 2 & (Z)-hex-3-en-1-ol + (E)-hex-3-en-1-ol + (Z)-hex-2-en-1-ol + (E)-hex-2-enal & $14.5 \mathrm{~b}$ & $10.14 \mathrm{~b}$ \\
\hline 3 & (E)-hex-2-enyl acetate + hexyl acetate & $2.7 \mathrm{a}$ & $47.69 \mathrm{~d}$ \\
\hline 4 & meso-butane-2,3-diol + butane-1,2-diol + butane-1,3-diol + butane-1,4-diol & $34.2 \mathrm{c}$ & $28.88 \mathrm{c}$ \\
\hline 5 & 3-hydroxybutan-2-one + 4-hydroxybutan-2-one & $17.7 \mathrm{~b}$ & $10.62 \mathrm{~b}$ \\
\hline 6 & Linalil acetate + nerolidol & $13.1 \mathrm{~b}$ & $2.08 \mathrm{a}$ \\
\hline 7 & Tween 80 (control) $)^{2}$ & $0.0 \mathrm{a}$ & $0.00 \mathrm{a}$ \\
\hline 8 & Tween 80 (control of the in vitro assay) ${ }^{3}$ & $0.0 \mathrm{a}$ & $0.00 \mathrm{a}$ \\
\hline
\end{tabular}

${ }^{1}$ Values followed by the same letter do not differ significantly according to the Scott \& Knott test $(P \leq 0.05)$; ${ }^{2}$ Extract of plants sprayed with a solution of Tween 80 at $0.01 \mathrm{~g} \mathrm{~mL}^{1} ;{ }^{3} \mathrm{An}$ aqueous solution of Tween 80 at $0.01 \mathrm{~g} \mathrm{~mL}^{-1}$ was directly used as a control in the in vitro assay; ${ }^{4} \mathrm{VOC}$ concentrations in $\mathrm{mmol} \mathrm{L}^{-1}$.

higher in the roots of plants exposed to treatment 3 at 0.5 $\mathrm{mmol} \mathrm{L}^{-1}$ (Figure 1). An opposite result was expected, since among the more than 900 amino acids produced by plants (Bell, 2003), many structures are directly active against plant pathogens (Rosenthal, 2001), including nematodes (Oliveira et al., 2009). Thus, it seems that roots of plants exposed to treatment 3 at $1.0 \mathrm{mmol} \mathrm{L}^{-1}$, which increased the mortality of $\mathrm{J} 2$ exposed to the root extracts, should produce higher amounts of amino acids.

At first glance this lack of correlation between the concentrations of VOC in treatment 3 and the metabolite production by coffee plants and the number of galls of the nematode in the roots may seem strange. However, the lack of correlation between the biological activity and the concentration of plant hormones and analogues is common.
For example, chlorophenoxy compounds along with certain benzoic and picolinic acid derivatives are growth regulators with hormone-like activity. At low dosage they bring about growth responses in regions distant from the point of application, but at higher dosage they may be used as herbicides. When used at a very high dosage, they cause excessive contact injury to the foliage, resulting in little translocation, which reduces the efficiency of the weed control (Ashton \& Crafts, 1973).

The concentrations of total soluble carbohydrates increased in the roots of plants exposed to treatment 3 at both concentrations (Figure 1), which may have caused the overexpression of plant defense genes such as those related to the biosynthesis of chalcone synthase or proteinase inhibitors (Johnson \& Ryan, 1990; Tsukaya et al., 1991). Conversely, 
the concentrations of phenols decreased (Figure 1), which was unexpected, since the direct activities of phenols against plant parasitic nematodes have been reported by various researchers (Choi et al., 2007; Takaishi et al., 2004). For example, tomato plants (S. lycopersicum) resistant to $M$. incognita produce more phenols than the susceptible cultivar (Campos et al., 2012). Even the concentration of chlorogenic acid, which is a phenol thought to be the cause of the resistance of tomato plants to M. incognita (Hung \& Rohde, 1973), was reduced by treatment 3 (Figure 2). The concentration of citric acid reached the maximum value in the roots of plants exposed to treatment 3 at $0.5 \mathrm{mmol} \mathrm{L}^{-1}$ (Figure 2). As this substance is active in vitro against $M$. incognita and Rotylenchulus reniformis Linford and Oliveira (Zuckerman et al., 1994), it may have contributed to the decrease of the number of $M$. exigua galls in the roots of coffee plants exposed to treatment 3.

The combination of meso-butane-2,3-diol + butane-1,2-diol + butane-1,3-diol + butane-1,4-diol, at $0.5 \mathrm{mmol} \mathrm{L}^{-1}$ (treatment 4; Table 1), also reduced the number of galls of $M$. exigua in coffee roots, and values were statistically equal to those observed for plants exposed to treatment 3 . The effect of these diols appears to be in accordance with the reported ability of butane2,3-diol, produced by Bacillus sp., to activate defense genes in Arabidopsis sp (Farag et al., 2006; Ryu et al., 2003; Ryu et al., 2004). However, when the concentration of these diols was increased to $1.0 \mathrm{mmol} \mathrm{L}^{-1}$ (treatment 4 ), no reduction in the nematode population was observed in relation to the control treatment. Similar to the observations of treatment 3 , small alterations in the concentrations of VOC may cause different responses in coffee plants.

When exposed to root extracts from plants sprayed with treatment 4 , a higher percentage of dead J2 was observed (Table 3), suggesting that the corresponding VOC induced the production of non-volatile nematicidal substances by plants. However, treatment 4 at $1.0 \mathrm{mmol}$ $\mathrm{L}^{-1}$ did not reduce the number of nematode galls in coffee plants (Table 1). Perhaps the production of nematicidal substances is not the only prerequisite to control the nematode. The parasite also has to get in contact with these substances, what may not have happened in plants exposed to treatment 4 at the higher concentration. A similar result was observed when root exudates from plants susceptible to root-knot nematodes were used in in vitro assays with Meloidogyne spp. J2 (Rocha et al., 2005). Various exudates increased the J2 mortality, suggesting that plants susceptible to plant-parasitic nematodes may also produce nematicidal substances.

Regarding the combination of (Z)-hex-3-en-1-ol + (E)-hex-3-en-1-ol + (Z)-hex-2-en-1-ol + (E)-hex-2-enal (treatment 2$)$, at both concentrations $(0.5$ and $1.0 \mathrm{mmol}$ $\left.\mathrm{L}^{-1}\right)$ these substances reduced the nematode population in coffee plants (Table 1). In the in vitro assay, only the combination of these substances afforded values of dead M. exigua $\mathrm{J} 2$ above the control when VOC concentration was $1.0 \mathrm{mmol} \mathrm{L}^{-1}$ (Table 2), suggesting that they could have translocated from leaves to roots to directly act against the nematode. As this study was directed toward the alterations in the production of non-volatile metabolites caused in coffee plants by VOC, most of the volatile substances were removed as the plant extracts were prepared. Consequently, the translocation of VOC in treatment 2 could not be evaluated in the present work. However, as the concentration of (Z)-hex-3-en-1-ol, one of the components of treatment 2, is lower in the roots of plants exposed to such treatment (Figure 2) than in the roots of plants sprayed with the control, it appears that these substances do not act directly against the nematode in plant roots. These results are in agreement with the induction of various defense genes in Arabidopsis thaliana (L.) Heynh by (E)-hex-2-enal (Bate \& Rothstein, 1998). It is also known that exposure of $A$. thaliana to (E)hex-2-enal, (Z)-hex-3-enal or (Z)-hex-3-enol increases the resistance to the fungus Botrytis cinerea (De Bary) Whetzel (Kishimoto et al., 2005).

The percentages of dead J2 after in vitro exposure to extracts of roots from plants sprayed with treatment 2 at both concentrations were statistically different from the control (Table 3). As various alkaloids show nematicidal activity (Chitwood, 2002), it seemed reasonable that these substances could be the component of the extract toxic to M. exigua $\mathrm{J} 2$, but the concentration of alkaloids in roots of plants sprayed with treatment 2 at $1.0 \mathrm{mmol} \mathrm{L}^{-1}$ was statistically equal to the control, while for those plants treated with the same VOC at $0.5 \mathrm{mmol} \mathrm{L}^{-1}$ the concentration of alkaloids was about $61 \%$ lower than that observed for the control (Figure 1). A similar behavior was observed for other substances (amino acids, phenols etc.) that could be responsible for the nematicidal activity of the extract.

The combination of 3-hydroxybutan-2-one + 4-hydroxybutan-2-one (treatment 5) at $0.5 \mathrm{mmol} \mathrm{L}^{-1}$ also reduced the nematode population (Table 1). As substances in this treatment did not affect the in vitro mortality of $M$. exigua (Table 2), apparently they acted indirectly against the nematode, which is in accordance with the ability of the first substance and their analogues to activate defense genes in Arabidopsis sp. (Ryu et al., 2003; Ryu et al., 2004; Farag et al., 2006). This combination of VOC at $0.5 \mathrm{mmol} \mathrm{L}{ }^{-1}$ increased the concentration of trigonelline (Figure 2), which can induce defense genes in plants (Kraska \& Schoenbeck, 1992). They also induced plants to produce nematicidal substances, since root extract of plants exposed to this treatment increased the in vitro mortality of J2 (Table 3). Perhaps carbohydrates may account for this nematicidal activity because their concentrations in the roots sprayed with treatment 5 at $0.5 \mathrm{mmol} \mathrm{L}^{-1}$ were higher than that observed for the control (Figure 1) and, as reported elsewhere, carbohydrates may present nematicidal activity against $M$. exigua (Oliveira et al., 2007).

Despite the reduction of the number of nematode 
galls by treatment 5 at $0.5 \mathrm{mmol} \mathrm{L}^{-1}$, when the concentration of their components was increased to $1.0 \mathrm{mmol} \mathrm{L}^{-1}$ the number of galls increased to a value statistically equal to the control (Table 1). This result corroborates the similar behavior observed for treatment 4 . Conversely, the increase in the concentrations of $\mathrm{VOC}$ in treatment 1 (jasmone + methyl jasmonate) reduced the number of galls. According to the literature the components of treatment 1 can induce defense genes in plants (Bate \& Rothstein, 1998). Jasmonic acid can induce the resistance of $S$. lycopersicum against M. incognita and M. javanica (Cooper et al., 2005), while the application of methyl jasmonate to $S$. lycopersicum decreases the infection of $M$. incognita (Fujimoto et al., 2011)

The principal component analysis (Figure 3 ) shows that metabolite concentrations in roots of coffee plants exposed to the combination of jasmone + methyl jasmonate (treatment 1) are different from that observed for the other treatments, suggesting that the mode of action of these VOC are also different. The mode of action of the combination of (Z)-hex-3-en-1-ol + (E)-hex-3-en-1-ol + (Z)-hex-2-en-1-ol + (E)-hex-2-enal (treatment 2) also tended to be different from the other VOC, especially at the lowest concentration $\left(0.5 \mathrm{mmol} \mathrm{L}^{-1}\right)$. Regarding the other combinations of VOC, the metabolic profile of roots tended to be close, suggesting similarity in the mechanism of action of these VOC.

In conclusion, combinations of jasmone + methyl jasmonate (treatment 1), (Z)-hex-3-en-1-ol + (E)-hex-3en-1-ol $+(Z)$-hex-2-en-1-ol + (E)-hex-2-enal (treatment 2), (E)-hex-2-enyl acetate + hexyl acetate (treatment 3), meso-butane-2,3-diol + butane-1,2-diol + butane-1,3-diol + butane-1,4-diol (treatment 4) and 3-hydroxybutan-2-one + 4-hydroxybutan-2-one (treatment 5) have potential to be used in the development of new products for controlling $M$. exigua in coffee plants. Although the mode of action of these VOC combinations have not been elucidated, the results suggest they are inducing plants to carry out metabolic transformations to reduce nematode population. The effects of these VOC on the nematode and on the metabolic variation in plant roots were very dependent on the concentration of the volatile substances sprayed on the aerial parts of coffee plants. Therefore, further studies are needed to better understand the mode of action of these substances and to establish the best combination of VOC and their concentration to obtain an efficient product to control M. exigua in coffee plants.

\section{ACKNOWLEDGEMENTS}

The authors are grateful to Fundação de Amparo à Pesquisa do Estado de Minas Gerais (FAPEMIG), Conselho Nacional de Desenvolvimento Científico e Tecnológico (CNPq) and Coordenação de Aperfeiçoamento de Pessoal de Nível Superior (CAPES), for financial support, and thank the Brazilian Biosciences National Laboratory (LNBio/ CNPEM) for access to the NMR facility.

\section{REFERENCES}

Amaral DR, Oliveira FER, Oliveira DF (2003) Purification of two substances from bulbs of onion with nematicidal activity against Meloidogyne exigua Goeldi. Nematology 5:859-864.

AOAC (1960) Association of Official Analytical Chemists. Official Methods of Analysis 5:264-265.

Arimura G, Kost C, Boland W (2005) Herbivore-induced, indirect plant defences. Biochimica et Biophysica Acta (BBA) - Molecular and Cell Biology of Lipids 1734:91-111.

Ashton FM, Crafts AS (1973) Mode of Action of Herbicides. New York NY, USA. John Wiley and Sons Inc.

Barbosa DHSG, Vieira HD, Souza RM, Viana AP, Silva CP (2004) Field estimates of coffee yield losses and damage threshold by Meloidogyne exigua. Nematologia Brasileira 28:49-54.

Bate NJ, Rothstein SJ (1998) C-6 volatiles derived from lipoxygenase pathway induce a subset of defense-related genes. Plant Journal 16:561-569.

Bell EA (2003) Nonprotein amino acids of plants: significance in medicine, nutrition, and agriculture. Journal of Agricultural and Food Chemistry 51:2854-2865.

Caboni P, Ntalli NG, Aissani N, Cavoski I, Angioni A (2012) Nematicidal activity of (E,E)-2,4-decadienal and (E)-2-decenal from Ailanthus altissima against Meloidogyne javanica. Journal of Agricultural and Food Chemistry 60:1146-1151.

Campos VAC, Machado ART, Oliveira DF, Campos VP, Chagas RCR, Nunes AS (2012) Changes in metabolites in plant roots after inoculation with Meloidogyne incognita. Nematology 14:579588.

Campos VP, Silva JRC (2008) Management of Meloidogyne spp. in coffee plantations. In: Souza RM (Ed.) Plant-Parasitic Nematodes of Coffee. Springer. ISBN 9781402087196. pp. 149-164.

Campos VP, Villain L (2005) Nematode parasites of coffee and cocoa. In: Luc M, Sikora RA, Bridge J (Eds.) Plant-Parasitic Nematodes in Subtropical and Tropical Agriculture. Wallingford UK. CABI Publishing. pp.529-579.

Chitwood DJ (2002) Phytochemical based strategies for nematode control. Annual Review of Phytopathology 40:221-249.

Choi I, Kim J, Shin S, Park I (2007) Nematicidal activity of monoterpenoids against the pine wood nematode (Bursaphelenchus xylophilus). Russian Journal of Nematology 15:35-40.

Cooper WR, Jia L, Goggin L (2005) Effects of jasmonateinduced defenses on root-knot nematode infection of resistant and susceptible tomato cultivars. Journal of Chemical Ecology 31:1953-1967.

Engelberth J, Alborn HT, Schmelz EA, Tumlinson JH (2004) Airborne signals prime plants against herbivore attack. Proceedings of the National Academy of Sciences, USA 101:1781-1785.

Farag MA, Ryu CM, Sumner LW, Paré PW (2006) GC-MS SPME profiling of rhizobacterial volatiles reveals prospective inducers of growth promotion and induced systemic resistance in plants. Phytochemistry 67:2262-2268.

Fujimoto T, Tomitaka Y, Abe H, Tsuda S, Futai K, Mizukubo T (2011) Expression profile of jasmonic acid-induced genes and the induced resistance against the root-knot nematode (Meloidogyne 
incognita) in tomato plants (Solanum lycopersicum) after foliar treatment with methyl jasmonate. Journal of Plant Physiology 168:1084-1097.

Heil M, Kost C (2006) Priming of indirect defences. Ecology Letters 9:813-817.

Hung C, Rohde RA (1973) Phenol accumulation related to resistance in tomato to infection by root-knot and lesion nematodes. Journal of Nematology 5:253-258.

Hussey RS, Barker KR (1973) A comparison of methods of collecting inocula of Meloidogyne spp including a new technique. Plant Disease Reporter 57:1025-1028.

Ibraim SK, Traboulsi AF, EL-Haj S (2006) Effect of essential oils and plant extracts on hatching, migration and mortality of Meloidogyne incognita. Phytopathologia Mediterranea 45:238246.

Ikeda Y, Koizumi N, Kusano T, Sano H (1999) Sucrose and cytokinin modulation of WPK4, a gene encoding a SNF1-related protein kinase from Wheat. Plant Physiology 121:813-820.

Johnson R, Ryan CA (1990) Wound-inducible potato inhibitor II genes: Enhancement of expression by sucrose. Plant Molecular Biology 14:527-536.

Keeling CI, Bohlmann KJ (2006) Genes, enzymes and chemicals of terpenoid diversity in the constitutive and induced defence of conifers against insects and pathogens. New Phytologist 170:657675 .

Kim H, Chen F, Wang X, Rajapakse NC (2006) Effect of methyl jasmonate on secondary metabolites of sweet basil (Ocimum basilicum L.). Journal of Agricultural and Food Chemistry 54:2327-2332.

Kishimoto K, Matsui K, Ozawa R, Takabayashi J (2005) Volatile C6-aldehydes and allo-ocimene activate defense genes and induce resistance against Botrytis cinerea in Arabidopsis thaliana. Plant Cell Physiology 46:1093-1102.

Kishimoto K, Matsui K, Ozawa R, Takabayashi J (2006) Components of C6-aldehyde-induced resistance in Arabidopsis thaliana against a necrotrophic fungal pathogen, Botrytis cinerea. Plant Science 170:715-723.

Kost C, Heil M (2006) Herbivore-induced plant volatiles induce an indirect defence in neighbouring plants. Journal of Ecology 94:619-628.

Kraska T, Schoenbeck F (1992) Resistance induction in plants by trigonellineandpossiblemechanisms. In:TyihakE(Ed.)Proceedings of the 3rd International Conference on Role of Formaldehyde in Biological Systems: Methylation and Demethylation Processes. Sopron Hungary. Hungarian Biochemical Society. pp. 163-168.

Lohar DP, Schaff JE, Laskey JG, Kieber JJ, Bilyeu KD, Bird DM (2004) Cytokinins play opposite roles in lateral root formation, and nematode and rhizobial symbioses. Plant Journal 38:203-214.

Lordello RLA, Lordello LGE (1983) Desenvolvimento de Meloidogyne exigua Goeldi, 1887, em raízes de cafeeiros, em três ambientes. Anais da Escola Superior de Agricultura "Luiz de Queiroz" 40:271-295.

Martin D, Tholl D, Gershenzon J, Bohlmann J (2002) Methyl jasmonate induces traumatic resin ducts, terpenoid resin biosynthesis, and terpenoid accumulation in developing xylem of Norway spruce stems. Plant Physiology 129:1003-1018.
Ntalli NG, Ferrari F, Giannakou I, Menkissoglu-Spiroudi U (2011) Synergistic and antagonistic interactions of terpenes against Meloidogyne incognita and the nematicidal activity of essential oils from seven plants indigenous to Greece. Pest Management Science 67:341-351.

Oliveira DF, Carvalho HWP, Nunes AS, Silva GH, Cavalheiro AJ, Campos VP (2007) Atividade de carboidrato purificado a partir da cebola (Allium cepa L.) e de carboidratos comerciais sobre juvenis de Meloidogyne exigua Goeldi. Nematologia Brasileira 31:202209.

Oliveira DF, Hudson WPC, Nunes AS, Silva GH, Campos VP, Júnior HMS, Cavalheiro AJ (2009) The activity of amino acids produced by Paenibacillus macerans and from commercial sources against the root-knot nematode Meloidogyne exigua. European Journal of Plant Pathology 124:57-63.

Paré PW, Farag MA, Krishnamachari V, Zhang H, Ryu CM, Kloepper JW (2005) Elicitors and priming agents initiate plant defense responses. Photosynthesis Research 85:149-159.

Paré PW, Tumlinson JW (1999) Plant volatiles as a defense against insect herbivores. Plant Physiology 121:325-331.

Passos LP (1996) Métodos Analíticos e Laboratoriais em Fisiologia Vegetal. Coronel Pacheco MG, Brazil. Embrapa Gado de Leite.

Ren X, Kong Q, Wang P, Jiang F, Wang H, Yu T, Zheng X (2011) Molecular cloning of a PR-5 like protein gene from cherry tomato and analysis of the response of this gene to abiotic stresses. Molecular Biology Reports 38:801-807.

Rocha FS, Campos VP, Dutra MR, Nunes AS, Silva JRC (2005) Ação de exsudatos radiculares de plantas na eclosão, motilidade, mortalidade e penetração de juvenis de Meloidogyne incognita. Summa Phytopathologica 31:187-193.

Roda Al, Baldwin IT (2003) Molecular technology reveals how the induced direct defenses of plants work. Basic and Applied Ecology 4:15-26.

Rodriguez-Saona C, Crafts-Brandner SJ, Paré PW, Henneberry TJ (2001) Exogenous methyl jasmonate induces volatile emissions in cotton plants. Journal of Chemical Ecology 27:679-695.

Rose USR, Manukian A, Heath RR, Tumlinson JH (1996) Volatile semiochemicals released from undamaged cotton leaves - A systemic response of living plants to caterpillar damage. Plant Physiology 111:487-495.

Rosenthal GA (2001) L-Canavanine: a higher plant insecticidal allelochemical. Amino Acids 21:319-330.

Ruther J, Kleier S (2005) Plant-plant signaling: Ethylene synergizes volatile emission in Zea mays induced by exposure to (Z)-3-hexen-1-ol. Journal of Chemical Ecology 31:2217-2222.

Ryu C, Farag MA, Hu C, Reddy MS, Kloepper JW, Paré PW (2004) Bacterial volatiles induce systemic resistance in Arabidopsis. Plant Physiology 134:1017-1026.

Ryu C, Farag MA, Hu C, Reddy MS, Wei H, Paré PW, Kloepper JW (2003) Bacterial volatiles promote growth in Arabidopsis. Proceedings of the National Academy of Sciences, USA 100:49274932.

Scott AJ, Knott MAA (1974) Cluster analyses method for grouping means in the analyses of variance. Biometrics 30:502-512.

Simons V, Morrissey JP, Latijnhouwers M, Csukai M, Cleaver A, Yarrow C, Osbourn A (2006) Dual effects of plant steroidal 
alkaloids on Saccharomyces cerevisiae. Antimicrobial Agents and Chemotherapy 50:2732-2740.

Soriano IR, Asenstorfer RE, Schmidt O, Riley IT (2004) Inducible flavone in Oats (Avena sativa) is a novel defense against plantparasitic nematodes. Phytopathology 94:1207-1214.

Sreevidya N, Mehrotra S (2003) Spectrophotometric method for estimation of alkaloids precipitable with Dragendorff's reagent in plant materials. The Journal of AOAC International 86:11241127.

Takaishi K, Alen Y, Kawazu K, Baba N, Nakajima S (2004) Synthesis and antinematodal activity of 3-n-akylphenols.
Bioscience, Biotechnology and Biochemistry 68:2398-2400.

Tsukaya H, Ohshima T, Naito S, Chino M, Komeda Y (1991) Sugar-dependent expression of the CHS-A gene for chalcone synthase from petunia in transgenic Arabidopsis. Plant Physiology 97:1414-1421.

Whitehead AG, Heming JR (1965) A comparison of some quantitative methods of extracting small vermiform nematodes from soil. Annals of Applied Biology 55:25-38.

Zuckerman BM, Matheny M, Acosta N (1994) Control of plantparasitic nematodes by a nematicidal strain of Aspergillus niger. Journal of Chemical Ecology 20:33-43.

TPP 2013-0045 - Received 3 April 2013 - Accepted 24 June 2013

Section Editor: Cláudio Marcelo G. de Oliveira 